\title{
Relationship of Night Shift Work and Breast Cancer
}

Arnold Fernando ${ }^{1}$, Muhammad Ilyas ${ }^{1-2}$, Indah Suci Widyahening ${ }^{1-2}$

${ }^{1}$ Occupational Medicine Specialist Program, Faculty of Medicine, Universitas Indonesia, Jakarta, Indonesia

${ }^{2}$ Department of Community Medicine, Faculty of Medicine, Universitas Indonesia, Jakarta, Indonesia

Correspondence address: Arnold Fernando

E-mail: arnold.fernando@alumni.ui.ac.id

\begin{abstract}
Background. Breast cancer is the most common cancer among women worldwide. $80 \%$ of breast cancer that has been identified in Indonesia has progressed into an advanced stage of malignancy. In 2007, the International Agency for Research on Cancer concluded: shift-work that involves circadian disruption is probably carcinogenic to humans (Group 2A)

Aim. This study aims to justify the association between night shift work and breast cancer.

Methods. Searching literature for the evidence-based has been conducted with a clinical question through "PICO" method. Then continued with literature searching using the electronic database "PubMed" and "google scholar" search engine. The keyword is "shift work" "night shift" "breast cancer" and combined with MeSH terms and Boolean operation. The inclusion criteria are research on humans, and the exclusion is inaccessible studies, case report studies, and retracted articles.

Result. All of the ten prospective studies that have been combined, the weighted average RR was $0.99(95 \% \mathrm{CI}=0.95$ to 1.03$)$ for any night shift work compared with none. There was no statistically significant heterogeneity across studies $(\mathrm{P}=.052)$. ). But if based on a study of more than 20 years, the RR was 1.01 (95\% CI $=0.93$ to 1.10 ). And if based on a study of more than 30 years, the combined $\mathrm{RR}$ was $1.00(95 \% \mathrm{CI}=0.87$ to 1.14 , P heterogeneity $=0.067$. Confidence intervals for the incidence rate ratios on this study are narrow, even for 20 or more years of night shift work (RR $=1.01,95 \%$ $\mathrm{CI}=0.93$ to 1.10 ), so these findings exclude a moderate association of breast cancer incidence with long duration night shift work
\end{abstract}

Conclusion. There are insignificant associations between night shift work and breast cancer.

Keywords. Night shift, breast cancer, circadian rhythm, nurse, healthcare worker

\section{Introduction}

Breast cancer is the most common cancer among women worldwide. The noticeably higher prevalence in industrialized nations than developing countries suggests that modern society's environmental aspects may play an important role in breast cancer etiology. ${ }^{1}$ In Indonesia, breast cancer incidence is estimated 12/100.000 women based on histopathology data from the Indonesian Association of Pathologists (Perhimpunan Dokter Spesialis Patologi Indonesia) and the Indonesian Cancer Foundation (Yayasan Kanker Indonesia). Furthermore, around $80 \%$ of breast cancer cases identified in Indonesia have progressed into an advanced malignancy stage, which is more difficult to treat, low quality of life, and high mortality life rather than on early stage. In 2007, the International Agency for Research on Cancer concluded: shiftwork that involves circadian disruption is probably carcinogenic to humans (Group 2A), ${ }^{3}$ The circadian rhythm is a major body rhythm with regular ups and downs in the 24-hour day. Many systems in the body are very active at certain times of day, and not active at other times of the day.

Hospital nurse is one of occupation that doing shiftwork, they usually work on different shiftwork schedules, long shift, and even extra workdays. That working condition might increase the incidence of breast cancer among female nurses. Even though IARC has 
concluded that circadian disruption is probably carcinogenic, but it is still unclear whether is it circadian disruption that take the major role to triggered breast cancer among hospital nurses, or it was triggered by another factor such as genetic, lifestyle, and reproductive history.

The aim of this study is to find a solid and recent evidence how much is the association between night shift work and breast cancer, since there is quite lot of female workers work on night shift. So, if there is a breast cancer cases on female workers who work with night shift condition, an occupational doctor can diagnose is it the breast cancer cases is work related such as caused by night shift work or not related by his/her shift work.

\section{Case Presentation}

Mrs X, a female who already work for 20 years as hospital ward nurse came to polyclinic with a chief complaint about a lump on her left breast that became bigger day by day, and recently she feels pain on her left breast. This is the first time she experienced this condition and acknowledge that she is not under any medical treatment. She also denied that none of her family members has a similar condition nor have cancer. She works in changing shiftwork conditions, where one workday split into three shifts (morningafternoon-night). Usually, she starts on 2day shiftwork in the morning then change into 2-day shiftwork in the afternoon and change into 2-day shift work in the nigh then she has 1 or 2 days for a break then repeat into morning shift again. That pattern may be changing because several factors such as personal request, substitute her peer workers, or special assignment by her superior. She scared about her condition because she has a friend who also a nurse but work on different hospital and have similar symptoms as her but have been diagnosed as breast cancer.

\section{Discussions}

Finding evidence for this case has been conducted by reviewing an article that has been collected using the keywords (breast cancer) AND ((shift work) OR (night shift)) and keywords for google scholar are "shift work" "night shift" "breast cancer". The inclusion criteria included human studies, using adult subjects, and relevant with this case. Exclusion criteria included case report articles, pathophysiological, opinion papers, and articles besides English and Indonesian.

Using these criteria, the article was shortlisted, and eventually all abstracts and title from the initial search results were screened and reviewed by reading the title and headlines of the first 10 pages of the results to confirm that they fulfilled the inclusion, exclusion criteria and related by a clinical question. 1 article has been included in quantitative synthesis, which is an systematic review by Travis RC, et al (2016) with the title "Night Shift Work and Breast Cancer Incidence: Three Prospective Studies and Meta-analysis of Published Studies". The critical appraisal of this study can be seen in the table below. 


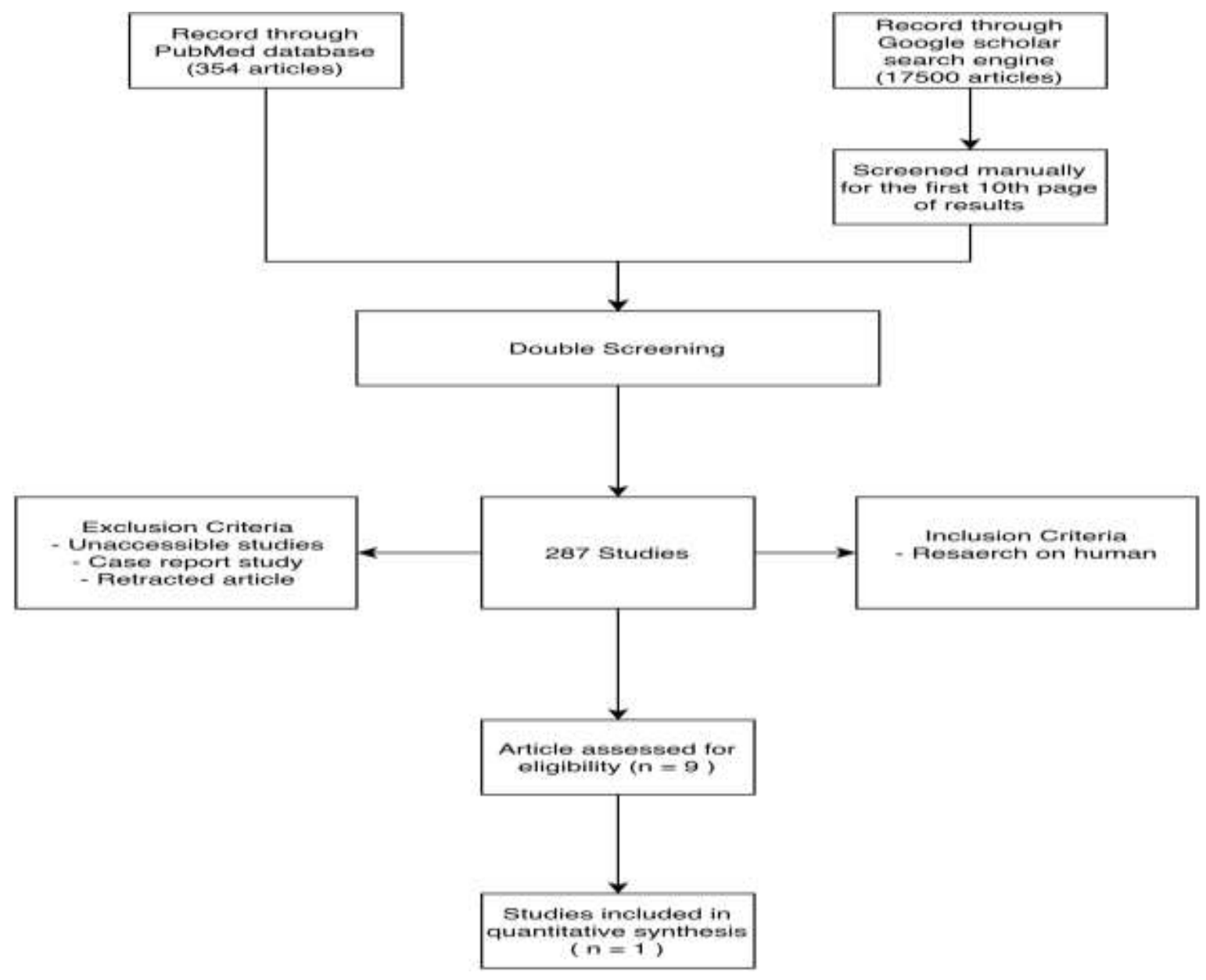

Figure 1. The process of article selection

Table 1. Critical appraisal of a meta-analysis study

\begin{tabular}{|c|c|}
\hline Appraisal Question & Travis RC, et al \\
\hline $\begin{array}{l}\text { Does the systematic review address a focused question } \\
\text { (PICO)? }\end{array}$ & Yes. \\
\hline $\begin{array}{l}\text { And use it to direct the search and select articles for } \\
\text { inclusion? }\end{array}$ & Yes. \\
\hline Find - Did the search find all the relevant evidence? & Yes. \\
\hline Appraise - Have the studies been critically appraised? & Unclear \\
\hline .....by more than one reviewer? & Not mentioned \\
\hline $\begin{array}{l}\text { Total up - Have the results been totaled up with appropriate } \\
\text { summary tables and plots? }\end{array}$ & $\begin{array}{l}\text { Yes. } \\
\text { Forest plot }\end{array}$ \\
\hline $\begin{array}{l}\text { Heterogeneity - ......and heterogeneity between studies } \\
\text { assessed and explained? }\end{array}$ & $\begin{array}{l}\text { Yes } \\
\text { Unweighted chi-squared tests } \\
\text { assessed heterogeneity across } \\
\text { studies }\end{array}$ \\
\hline $\begin{array}{l}\text { What were the results? - What measure was use, how large } \\
\text { was the effect (could it have been due to chance)? }\end{array}$ & $\begin{array}{l}4660 \text { breast cancers in women } \\
\text { reporting night shift work; } \\
\text { compared with other women, the } \\
\text { combined relative risks were } \\
0.99(95 \% \mathrm{CI}=0.95 \text { to } 1.03) \text { for } \\
\text { any night shift work, } 1.01 \text { (95\% }\end{array}$ \\
\hline
\end{tabular}


Travis RC, et al. has conducted a metaanalysis based on three prospective studies and 7 articles prospective studies from computer-aided literature searches using Scopus, PubMed/Medline, and Web of science. Then the authors examines all of these studies to determinate overall trends. ${ }^{5}$ This study aims to justify the association between night shift work and breast cancer. This report's conclusions are strengthened by the limited heterogeneity between studyspecific results, despite differences in design, population studied, exposure definition and assessment, night shift pattern, and control of potential confounders. Notably, while some studies focused on one occupation or industry, e.g. nurses ${ }^{6,7}$ or textile workers, others included participants from many occupations or the general population.

All of the ten prospective studies that have been combined, the weighted average $\mathrm{RR}$ was $0.99(95 \% \mathrm{CI}=0.95$ to 1.03$)$ for any night shift work compared with none. There was no statistically significant heterogeneity across studies $(\mathrm{P}=.052)$. Nevertheless, if based on the eight studies with 20 years or more of night shift work been reviewed, the $\mathrm{RR}$ was $1.01(95 \% \mathrm{CI}=0.93$ to 1.10$)$. On the other hand, the information on night shift work for more than 30 years was only available from four studies and the combined $\mathrm{RR}$ was $1.00(95 \% \mathrm{CI}=0.87$ to $1.14, \mathrm{P}$ heterogeneity $=0.067$. Confidence intervals for the incidence rate ratios on this study are narrow, even for 20 or more years of night shift work $(\mathrm{RR}=1.01,95 \% \mathrm{CI}=0.93$ to 1.10), so these findings exclude an association of breast cancer incidence with long duration night shift work.

\section{Discussions}

Based on systematic review that has been conducted by Travis, et al it is concluded that there is no evidence of any association of breast cancer incidence with night shift work and, in particular, no evidence of any increase in incidence with 20 or more years of night shift work

Travis, et al study is considered quite good to answer the clinical question between breast cancer and night shift work for female workers, they reviewed 3 large sample prospective studies in United Kingdom and meta analyses of 7 published relevant studies with concern of association night work shift and breast cancer. The RR of any shift work vs no night shift work were $0.99(95 \% \mathrm{CI}=$ 0.95 to 1.03 ), if compared to more than 20 years of night shift work the RR is $1.01(95 \%$ $\mathrm{CI}=0.93$ to 1.10 ), and even more 30 years or more the $\mathrm{RR}$ is $1.00(95 \% \mathrm{CI}=0.87$ to 1.14$)$.

The strength of this study is the large number of studies and the most recent of studies where night shift work and breast cancer was not the primary outcome when this study was conducted, the occupation that included in this study also varied such as nurses, cleaners, factory workers, bar workers, shop workers, cook/waitress, and flight attendant. Though there are several potential limitations of this study, which is unable to analyses the dose-response relationship between night shift work and breast cancer and there are several residual confounding factors such as obesity, life style (smoking and taking a medication to help them sleep), family history of cancer that cannot be excluded that may bias the results 
On Travis, et al study the incidence of breast cancer in the prospective study are still below 1000, which may be still can increasing if the subjects are still followed up, even though these cases were four times higher if compared to the 2007 IARC review. And then some confounding factors such as obesity, smoking habits, using a drug to help the subjects sleep, and prefer to work at the evening rather than morning may influence the results

The heterogeneity of the subjects is limited on Travis, et al study, for example the occupation of the subjects is vary even though some of the studies focus on some occupation, such as nurses or textile workers. Based on subjects that has been worked more than 10 years in night shift still give insignificant results of the incidence of breast cancer among night shift workers. This study also limited the article that can be examined in this meta-analysis study to minimize the confounding factors that may came from retrospective studies

The International Agency for Research on Cancer (IARC) concluded shift-work that involves circadian disruption is probably carcinogenic to human or categorized as group 2A in 2007, but it was based on limited epidemiological evidence and need to be follow up since the prospective evidence are now available to justify the association between night shift work and breast cancer. This study might be applicable in Indonesia, considering there are many workers who work at shift work condition. But because most of these studies that has been review are non-Asian countries some cofounding factors such as lifestyle and genetics may play the role to vary the results. This study can explain that shit work condition may affect the health condition. However, the chance of getting breast cancer is influenced by multiple factors besides shift work such as genetic factors, reproductive factors, lifestyle factors, obesity, and environmental risk factors (exposure of tobacco smoke, pesticides, radiation). ${ }^{8}$ That is why a promotive and preventive program must be offered to encourage the workers' management to minimize the factors in work condition that may increase the risk of breast cancer, such as elimination and substitution of material or hazard that may impact the workers and also providing personal protective equipment. Besides the workers' management, the workers must also make an effort to minimize the risk factors that can be changed especially the lifestyle factors like a smoking habit, dietary pattern, sedentary lifestyle, alcohol consumption, and medication.

\section{Conclusion and recommendation}

Based on the study that has been reviewed, there is insignificant associations between night shift work and breast cancer, though Similar studies need to be conducted in Asia especially in Indonesia to give a representation of night shift work and breast cancer with Asia or Indonesia characteristic. The workers' management to be expected to minimize all the hazard in work condition that may increase breast cancer risk. For example, elimination and substitution of material or hazard may impact the workers and provide personal protective equipment education to the workers are needed to encourage them to minimize the changeable risk factors, such as smoking habit, dietary pattern, sedentary lifestyle, alcohol consumption, and medication

\section{References}

1. Wegrzyn LR, Tamimi RM, Rosner BA, Brown SB, Stevens RG, Eliassen AH, et al. Rotating night-shift work and the risk of breast cancer in the nurses' health studies. Am J Epidemiol. 2017;186(5):532-40.

2. Rosa RR. Plain language about shiftwork. US Department of Health and Human Services, Public Health Service, Centers ...; 1997.

3. Straif K, Baan R, Grosse Y, Secretan B, El Ghissassi F, Bouvard V, et al. Carcinogenicity of shift-work, painting, and fire-fighting. Elsevier; 2007.

4. Hansen J. Night shift work and risk of breast cancer. Curr Environ Health Rep. 2017;4(3):325-39.

5. Travis RC, Balkwill A, Fensom GK, Appleby PN, Reeves GK, Wang X-S, et al. Night shift work and breast cancer incidence: three prospective studies and meta-analysis of published studies. JNCI J Natl Cancer Inst. 2016;108(12):djw169. 
6. Schernhammer ES, Laden F, Speizer FE, Willett WC, Hunter DJ, Kawachi I, et al. Rotating night shifts and risk of breast cancer in women participating in the nurses' health study. J Natl Cancer Inst. 2001;93(20):1563-8.

7. Schernhammer ES, Kroenke $\mathrm{CH}$, Laden F, Hankinson SE. Night work and risk of breast cancer. Epidemiology. 2006;108-11.

8. Breast Cancer: Practice Essentials, Background, Anatomy. 2020 Oct 10 [cited 2021 Jan 29]; Available from: https://emedicine.medscape.com/article/19 47145-overview\#a6. 
APPENDIX

\section{Critical appraisal of systematic review}

Title : Night shift work and breast cancer incidence: three prospective studies and metaanalysis of published studies

Authors : Travis RC, et al (2016)

\begin{tabular}{|c|c|}
\hline Appraisal Question & Answer \\
\hline Does the systematic review address a focused question (PICO)? & $\begin{array}{l}\text { Yes. } \\
\text { The study aim is to identify the } \\
\text { association between night shift } \\
\text { work and breast cancer }\end{array}$ \\
\hline And use it to direct the search and select articles for inclusion? & $\begin{array}{l}\text { Yes. } \\
\text { This study is reviewed multiple } \\
\text { meta-analysis studies and } \\
\text { multiple prospective studies to } \\
\text { justify the association between } \\
\text { night shift work and breast } \\
\text { cancer }\end{array}$ \\
\hline Find - Did the search find all the relevant evidence? & $\begin{array}{l}\text { Yes. } \\
\text { Yes, this meta-analysis } \\
\text { reviewed } 3 \text { UK prospective } \\
\text { studies and combine these and } \\
\text { relative risks from seven } \\
\text { previously published } \\
\text { prospective studies. The seven } \\
\text { previously publication were } \\
\text { identified using literature } \\
\text { searches through } \\
\text { MEDLine/PubMed, Scopus, } \\
\text { and Web of Science suing } \\
\text { combination of search terms } \\
\text { "shift work", "night work", } \\
\text { "breast cancer", "cohort", and } \\
\text { "prospective". The author also } \\
\text { mentioned that the seven } \\
\text { prospective studies that were } \\
\text { choose are meet the author } \\
\text { criteria such as 95 confidence } \\
\text { intervals and } 20 \text { or more years } \\
\text { of night shift work vs no night } \\
\text { shift work. On the } \\
\text { supplementary material the } \\
\text { authors also mentioned that they } \\
\text { followed standard criteria for } \\
\text { meta-analyses (MOOSE } \\
\text { guidelines) }\end{array}$ \\
\hline Appraise - Have the studies been critically appraised? & $\begin{array}{l}\text { Yes, this study using } 10 \\
\text { prospective studies where } \\
\text { exposure data were recorded } \\
\text { before the onset of breast cancer } \\
\text { and used heterogeneous }\end{array}$ \\
\hline
\end{tabular}


IJCOM 2021 July;1(1):15-22

\begin{tabular}{|c|c|}
\hline & $\begin{array}{l}\text { eligibility criteria in terms of the } \\
\text { exposure definitions, study } \\
\text { design and eligibility period }\end{array}$ \\
\hline .....by more than one reviewer? & $\begin{array}{l}\text { Yes, independently by two } \\
\text { researchers }\end{array}$ \\
\hline $\begin{array}{l}\text { Total up - Have the results been totaled up with appropriate } \\
\text { summary tables and plots? }\end{array}$ & $\begin{array}{l}\text { Yes. } \\
\text { This study presented a forest } \\
\text { plot and tables }\end{array}$ \\
\hline $\begin{array}{l}\text { Heterogeneity - ......and heterogeneity between studies assessed } \\
\text { and explained? }\end{array}$ & $\begin{array}{l}\text { Yes } \\
\text { Unweighted chi-squared tests } \\
\text { assessed heterogeneity across } \\
\text { studies and the result is there } \\
\text { was no statistically significant } \\
\text { heterogeneity across studies (P } \\
=.052 \text { ) }\end{array}$ \\
\hline $\begin{array}{l}\text { What were the results? - What measure was use, how large was } \\
\text { the effect (could it have been due to chance)? }\end{array}$ & $\begin{array}{l}\text { This meta-analysis of all } 10 \\
\text { prospective studies included } \\
4660 \text { breast cancers in women } \\
\text { reporting night shift work; } \\
\text { compared with other women, } \\
\text { the combined relative risks were } \\
0.99 \text { ( } 95 \% \mathrm{CI}=0.95 \text { to } 1.03 \text { ) for } \\
\text { any night shift work, } 1.01 \text { ( } 95 \% \\
\mathrm{CI}=0.93 \text { to } 1.10 \text { ) for } 20 \text { or more } \\
\text { years of night shift work, and } \\
1.00 \text { ( } 95 \% \mathrm{CI}=0.87 \text { to } 1.14 \text { ) for } \\
30 \text { or more years. }\end{array}$ \\
\hline How are the results presented? & $\begin{array}{l}\text { The totality of the prospective } \\
\text { evidence shows that night shift } \\
\text { work, including long-term shift } \\
\text { work, has little or no effect on } \\
\text { breast cancer incidence. }\end{array}$ \\
\hline
\end{tabular}

